\title{
Modification of poly(styrene-block-butadiene-block-styrene) [SBS] with phosphorus containing fire retardants
}

Chernyy, Sergey; Ullah, Saif; Jomaas, Grunde; Leisted, Rolff Ripke; Mindykowski, Pierrick Anthony; Ravnsbæk, Jens Bomholdt; Tordrup, Sie Woldum; Almdal, Kristoffer

\author{
Published in: \\ European Polymer Journal
}

Link to article, DOI:

10.1016/j.eurpolymj.2015.07.015

Publication date:

2015

Document Version

Peer reviewed version

Link back to DTU Orbit

Citation (APA):

Chernyy, S., Ullah, S., Jomaas, G., Leisted, R. R., Mindykowski, P. A., Ravnsbæk, J. B., Tordrup, S. W., \& Almdal, K. (2015). Modification of poly(styrene-block-butadiene-block-styrene) [SBS] with phosphorus containing fire retardants. European Polymer Journal, 70, 136-146. https://doi.org/10.1016/j.eurpolymj.2015.07.015

\section{General rights}

Copyright and moral rights for the publications made accessible in the public portal are retained by the authors and/or other copyright owners and it is a condition of accessing publications that users recognise and abide by the legal requirements associated with these rights.

- Users may download and print one copy of any publication from the public portal for the purpose of private study or research.

- You may not further distribute the material or use it for any profit-making activity or commercial gain

- You may freely distribute the URL identifying the publication in the public portal 


\title{
Modification of poly(styrene-block-butadiene-block-styrene) [SBS] with phosphorus containing fire retardants
}

\author{
Sergey Chernyy, ${ }^{1}$ Saif Ulah, ${ }^{1}$ Grunde Jomaas, ${ }^{2}$ Rolff Ripke Leisted, ${ }^{2}$ Pierrick Anthony \\ Mindykowski, ${ }^{2}$ Jens Bomholdt Ravnsbæk, ${ }^{3}$ Sie Woldum Tordrup, ${ }^{3}$ Kristoffer Almdal ${ }^{1}$
}

${ }^{1}$ Technical University of Denmark, DTU Nanotech - Department of Micro- and Nanotechnology, Produktionstorvet, 2800 Kgs. Lyngby, Denmark

${ }^{2}$ Technical University of Denmark, Department of Civil Engineering, Brovej, 2800 Kgs. Lyngby, Denmark

${ }^{3}$ Danish Technological Institute, Aarhus, Teknologiparken, Kongsvang Allé 29, 8000 Aarhus, Denmark

\section{Corresponding author}

Sergey Chernyy

Tel.: + (45) 509-14-004

E-mail: sech@nanotech.dtu.dk

\section{Keywords}

Poly(styrene-block-butadiene-block-styrene) [SBS] copolymer, 9,10-dihydro-9-oxa-10phosphaphenanthrene-10-oxide (DOPO), fire retardant, thermoplastic elastic additive, epoxidation, cone calorimetry 


\section{Abstract}

An elaborate survey of the chemical modification methods for endowing highly flammable SBS with increased fire resistant properties by means of chemical modification of the polymer backbone with phosphorus containing fire retardant species is presented. Optimal conditions for free radical addition of the P-H containing fire retardants to a double bonds of poly(butadiene) block of SBS were found, affording varied degree of the modification (0.2-21 mol\%). Alternatively, a two-step procedure based on an epoxidation step followed by hydrolysis of the epoxides with phosphoric acid was developed resulting in 20 mol\% of poly(butadiene) block modification. Based on TGA results, organophosporus-modified SBS was found to be amenable to charring - a property which correlated directly with the reduced flammability of the modified polymer observed in Cone Calorimetry tests. Furthermore, conceptually novel application of the $\mathrm{H}_{3} \mathrm{PO}_{4}$ modified SBS as a fire retardant additive for bitumen material, in combination with synergetic melamine species, offered $25 \%$ better self-extinguishing properties of such formulation already at a low loading level of the fire retardant components (3.5 wt.\%).

\section{Introduction}

The range of applications of thermoplastic elastomer poly(styrene-block-butadiene-block-styrene) [SBS] includes its usage as an additive to materials where elasticity and strength is to be preserved at temperatures well below zero. The formation of physical cross-links or anchor points by glassy poly(styrene) domains in the matrix where SBS is dispersed while maintaining the overall flexibility rendered by rubbery poly(butadiene) chains accounts for the wide use of SBS as an additive to bitumen, footwear, car tires and other compatible materials. ${ }^{1-3}$

The inherent disadvantage of SBS, namely its flammability, could be overcome by using supplementary fire retardants added to the polymer matrix, such as aluminium hydroxide, magnesium hydroxide, colemanite, antimony oxide etc. However, high loadings (> 30 wt.\%) of the 
filler are needed to impair the flammability of the matrix to a sufficient level which may deleteriously affect the elastic properties of matrix itself. ${ }^{4}$

Chemical incorporation of phosphorus containing substituents into a polymer backbone has been shown to result in substantial improvement of fire retardation at low loading levels. ${ }^{5,6}$ For example, phosphorylation of the hydroxyl groups of poly(vinyl alcohol) with $\mathrm{H}_{3} \mathrm{PO}_{4}$ increased the char yield and limiting oxygen index (LOI) values for the modified polymer. ${ }^{7}$ Dialkyl/diaryl phosphates introduced to a poly(1,4-isoprene) backbone also increased the LOI values for the modified rubber. ${ }^{8}$ In addition, synthesized polyethers with chemically bound 10-dihydro-9-oxa-10phosphaphenanthrene-10-oxide (DOPO) derivatives were capable of scavenging reactive radicals from a fire and successfully prevent combustion. ${ }^{9}$ Somewhat relevant work was realized by Fu et al. with respect to the hydrosilylation reaction of SBS with polyhedral oligomeric silsesquioxane (POSS). ${ }^{10}$ POSS-modified SBS can be thought of as a potential fire resistant material because of high thermal stability and protective properties of the silica shell formed from silsesquioxanes upon their decomposition. ${ }^{11}$

In the present work the possibility of SBS modification with DOPO and $\mathrm{H}_{3} \mathrm{PO}_{4}$ fire retardants is elucidated for the first time. The approach was realized by one step free radical addition of $\mathrm{P}-\mathrm{H}$ bonds of DOPO to the double bonds of the poly(butadiene) block (PBD) in the SBS as well as by two step addition of $\mathrm{H}_{3} \mathrm{PO}_{4}$ to beforehand epoxidized SBS.

\section{Materials and Methods}

All chemicals were purchased from Sigma-Aldrich unless otherwise stated. Tetrahydrofuran (99.9\%), toluene (99.9\%), water (Milli-Q, $18 \mathrm{M} \Omega \mathrm{cm}$ ) were used as solvents. 9,10-Dihydro-9-oxa10-phosphaphenanthrene-10-oxide (DOPO, >97\%) was supplied by TCI America. Dimethyl phosphite (DMPP, 98\%), triphenylphosphine ( $\geq 95.0 \%$ ), lithium (granular, 99\%), tert-butyllithium (1.7 $\mathrm{M}$ in pentane), iodine monobromide ( $\mathrm{IBr}, 98 \%), 3$-chloroperbenzoic acid (MCPBA, $\leq 77 \%$ ) 
were used as received. Diphenylphosphine (DPP) was synthesized by reacting triphenylphosphine with lithium according to the literature described procedure ${ }^{12,13}$ and lithium diphenylphosphanide (DPP-Li) was obtained by titrating DPP solution in THF with tert-butyllithium at $0{ }^{\circ} \mathrm{C}$ affording a dark red colored solution. Dicumyl peroxide (DCP), benzoyl peroxide (BPO, 75\%), lauroyl peroxide (LPO) and 2,2'-azobisisobutyronitrile (AIBN) were used as free radical initiators. Poly(styrene-block-butadiene-block-styrene) [SBS] with 19 mol\% (32 wt.\%) of styrene, commercially known as Calprene ${ }^{\circledR}$ 411, was supplied by Icopal A/S.

Gel Permeation Chromatography (GPC). The molecular weight was determined using THF as an eluent (at $0.5 \mathrm{ml} / \mathrm{min}$ low rate) with a column set consisting of a $5 \mu \mathrm{m}$ precolumn and two $300 \times$ $8 \mathrm{~mm}$ columns (PLgel Mixed C and Mixed D). The system was equipped with a triple detector system (a combined Viscotek model 200 differential diffractive index (DRI) and differential viscosity detector plus a Viscotek model LD 600 right angle laser light scattering detector (RALLS)). Prior to the SEC analysis all samples were filtered on $0.45 \mu \mathrm{m}$ PTFE filter as $1 \mathrm{mg} / \mathrm{ml}$ solutions. 1,3,5-trimethyl-2, 4,6-tris (3,5-di-t-butyl-4-hydroxybenzyl) benzene (Irganox 1330,775 $\mathrm{g} / \mathrm{mol}$ ) was used as an internal calibration standard.

Free radical addition of P-H to SBS (R1). In a typical experiment 5.0 g SBS (63 mmol olefinic units) and $42.4 \mathrm{~g}$ DOPO (190 mmol, 3x excess relative to olefinic units) was dissolved in $150 \mathrm{ml}$ of toluene (deoxygenated by three freeze-pump-thaw cycles) by heating to $115{ }^{\circ} \mathrm{C}$ under argon. Then, $0.197 \mathrm{~g}$ (0.73 mmol) of DCP dissolved in $15 \mathrm{ml}$ deoxygenated toluene was added under argon. The reaction continued for $3 \mathrm{~h}$ and the product was precipitated into $1 \mathrm{~L}$ of methanol followed by reprecipitation from chloroform to methanol. The modified polymer was dried for $16 \mathrm{~h}$ at $50{ }^{\circ} \mathrm{C}$ under vacuum (1e-2 mbar) affording $5.1 \mathrm{~g}$ of the product with the degree of poly(butadiene) block (PBD) modification equal to 3 mol\%, yield 95\%. ${ }^{1} \mathrm{H}$ NMR spectra of DOPO modified SBS samples 
with the degree of modification ranging from 0.2 to 21 mol\% are collected in the Supporting Information (SI1).

Halogenation of SBS with IBr followed by reaction with lithium diphenylphosphanide DPP-Li (R2, R3). First, to a solution of 2.5 g SBS (32 mmol olefinic) in $75 \mathrm{ml}$ THF $6 \mathrm{~g}$ of IBr (28 mmol) in $20 \mathrm{ml}$ THF was added dropwise in the dark at $0{ }^{\circ} \mathrm{C} .{ }^{14}$ The product was precipitated in acetone and stored at $-17{ }^{\circ} \mathrm{C}$ for further use. Second, $1.2 \mathrm{~g}$ of halogenated SBS was dissolved in 20 $\mathrm{mL}$ of dry THF and then $15 \mathrm{ml}$ of ca. $1.5 \mathrm{M}$ solution of DPP-Li was added at $0{ }^{\circ} \mathrm{C}$. The temperature was allowed to rise to $25^{\circ} \mathrm{C}$ and the reaction was terminated after $3 \mathrm{~h}$ by precipitation into aqueous methanol. NMR spectra of the halogenated SBS and its adduct with DPP-Li are collected in the Supporting Information, SI2.

Epoxidation of SBS (R4). The epoxidation of SBS was realized by adding the solution of $3 \mathrm{~g}$ (13 mmol) MCPBA in chloroform to a solution of $2.5 \mathrm{~g}$ (32 mmol olefinic) SBS in $75 \mathrm{ml}$ chloroform at $0{ }^{\circ} \mathrm{C}$ (Scheme 1). ${ }^{15,16}$ The reaction was allowed to proceed for $16 \mathrm{~h}$ allowing the temperature gradually to rise from 0 to $25^{\circ} \mathrm{C}$. The resulting polymer was precipitated into methanol and reprecipitated from $\mathrm{CHCl}_{3}$ to methanol in order to remove 3-chlorobenzoic acid. The targeted degree of PBD block epoxidation was 41 mol\%, whereas the experimentally achieved epoxidation level was $21 \mathrm{~mol} \%$, as estimated from NMR (Supporting Information, SI3). Hence, the efficiency of MCPBA was 51 mol\%.

Ring opening of the epoxidized SBS with phosphoric acid (R7). $60 \mathrm{~g}$ of SBS with the degree of epoxidation of PBD block equal to $21 \mathrm{~mol} \%$ was dissolved in THF $(1500 \mathrm{ml})$ and $10 \mathrm{ml}$ of $6 \mathrm{M}$ $\mathrm{H}_{3} \mathrm{PO}_{4}$ (ca. 10x excess relative to epoxy) was added dropwise at room temperature. The resulting homogeneous mixture was refluxed at $80{ }^{\circ} \mathrm{C}$ for $16 \mathrm{~h}$ under nitrogen and the product was precipitated into excess of water followed by vacuum drying at $50{ }^{\circ} \mathrm{C}$ for another $16 \mathrm{~h}$. The product shows a major peak at $-0.66 \mathrm{ppm}$ in ${ }^{31} \mathrm{P}$ NMR as well as characteristic phosphoryl $\mathrm{P}=\mathrm{O}\left(1200 \mathrm{~cm}^{-1}\right)$ 
and P-OH (1040-910 $\mathrm{cm}^{-1}$ ) absorbance in ATR FT-IR (Supporting Information, SI4). The sample is further abbreviated as E1.

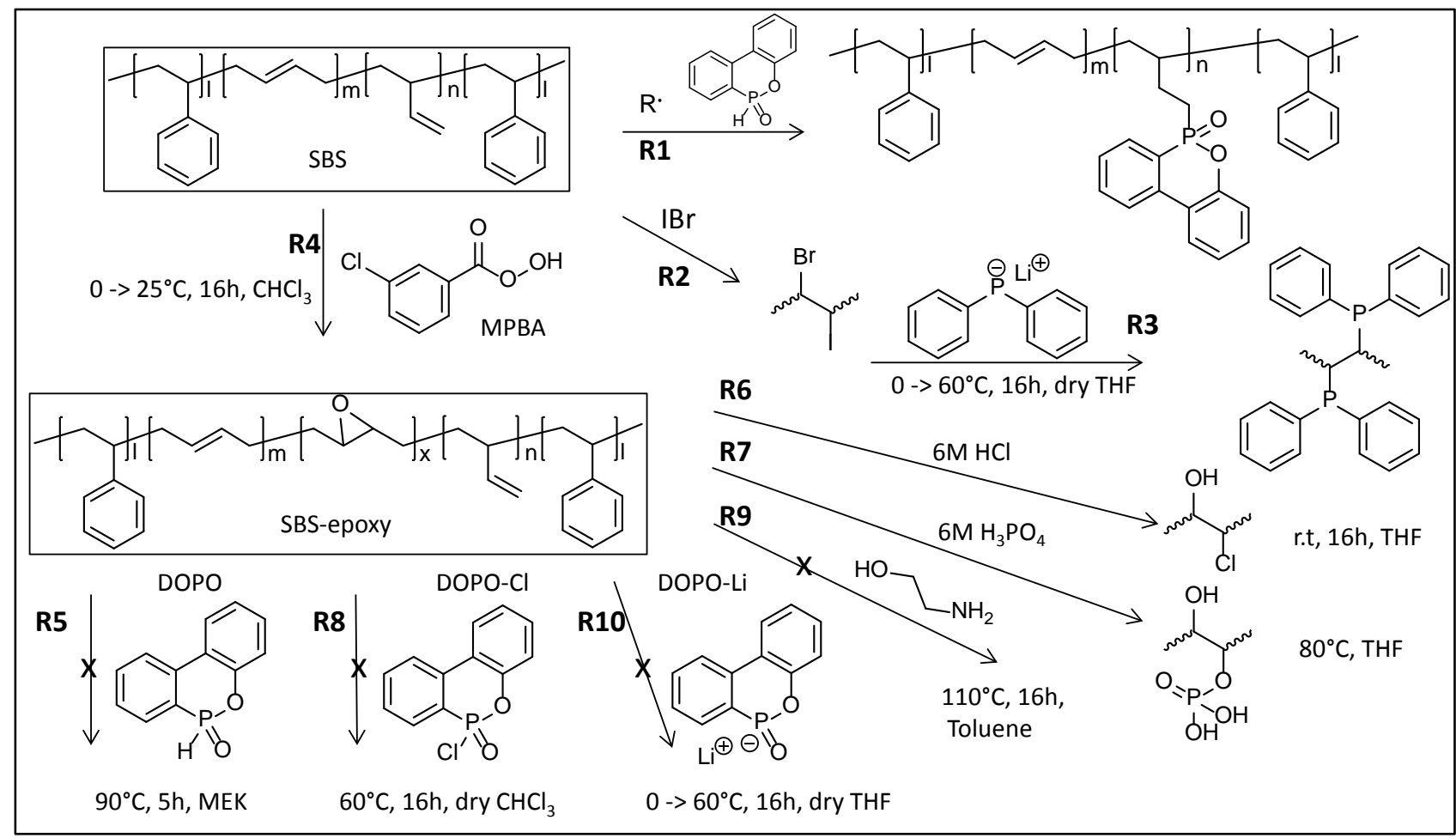

Scheme 1. The synthesis routes for modification of SBS with phosphorus containing species.

Cone calorimetry. The cone calorimetry experiments were performed according to ISO 5660, 2002: Reaction-to-fire tests - heat release, smoke production and mass loss rate using Mass Loss Cone (Fire Testing Technology, UK). Polymer plaques (5 x 100 x $100 \mathrm{~mm}$ ) were prepared by solvent casting of the concentrated polymer solutions in THF, followed by consequent drying under nitrogen at $60{ }^{\circ} \mathrm{C}$ for 1 day, at $80^{\circ} \mathrm{C}$ for 1 day and finally at $2 \mathrm{e}-3 \mathrm{mbar}\left(22^{\circ} \mathrm{C}\right)$ for 2 days. The optimal conditions for making the pallets with uniform thickness were found by trial and error.

Flammability tests for bitumen mixtures. In a typical experiment, $51 \mathrm{~g}$ of the $\mathrm{H}_{3} \mathrm{PO}_{4}$ modified SBS (Sample E1) was added into a mixture of bitumen (353 g) and chalk (343 g) along with equimolar relative to phosphoric acid monoester quantity of melamine (15 g). The melamine was used as a synergetic additive that formed ionic poly(melamine phosphate) species in-situ during the mixing process. A homogeneous mix was obtained after mechanical stirring for 20 min at $200{ }^{\circ} \mathrm{C}$. 
Furthermore, thin plaques $(5 \times 5 \times 0.2 \mathrm{~cm})$ of the bitumen modified in such way were prepared from a hot melt in order to test the flammability of the mixtures. The flammability behavior was assessed by either irradiating the plaque of bitumen located on the steel dish from the top using Epiradiator or by heating the sample from the bottom with a butane flame until the bitumen caught fire.

\section{Results and discussion}

Free radical addition of $\mathbf{P}-\mathbf{H}$ to SBS. The addition of modifiers with $\mathrm{P}-\mathrm{H}$ bonds prone to homolytic cleavage toward the olefinic units of SBS was realized using four types of free radical initiators, namely DCP, BPO, LPO and AIBN (Scheme 1, R1). The kinetics of DOPO addition was studied first using DCP only at $115{ }^{\circ} \mathrm{C}$. From the data in Table 1 and Figure 1 it is inferred that at high concentration of DCP $(10 \mathrm{mM})$ gelation of the reaction medium took place soon after the addition of initiator. The resulting degree of poly(butadiene) block (PBD) modification was as low as $1.8 \mathrm{~mol} \%$ and the molecular weight distribution became 3 times broader compared to unmodified SBS (Sample A2). The broadening of the molecular weight distribution (Figure 2) was attributed to the occurrence of cross-linking side-reactions via recombination of two radicals centered on polymer backbone which eventually led to the formation of a gel. It is thus reasonable to assume that by decreasing the initial concentration of DCP it will be possible to decrease the steady-state concentration of the radicals in the system and thereby diminish the rate of the biradical recombination reaction. Indeed, a decrease in the concentration of DCP from 10 to $5 \mathrm{mM}$ delayed the time of gelation from one to three hours and increased the degree of PBD modification from 1.8 to $3 \mathrm{~mol} \%$ (Sample A8). Furthermore, at $1 \mathrm{mM}$ of DCP the gelation was completely prevented even for prolonged reaction times $(20 \mathrm{~h})$. Hence, by varying the steady state concentration of free radicals in the reaction medium it was possible to control/prevent the onset of gelation as well as to 
achieve maximum, under these conditions, PBD block modification efficiency equal to 5.5 mol\% (Sample A9).
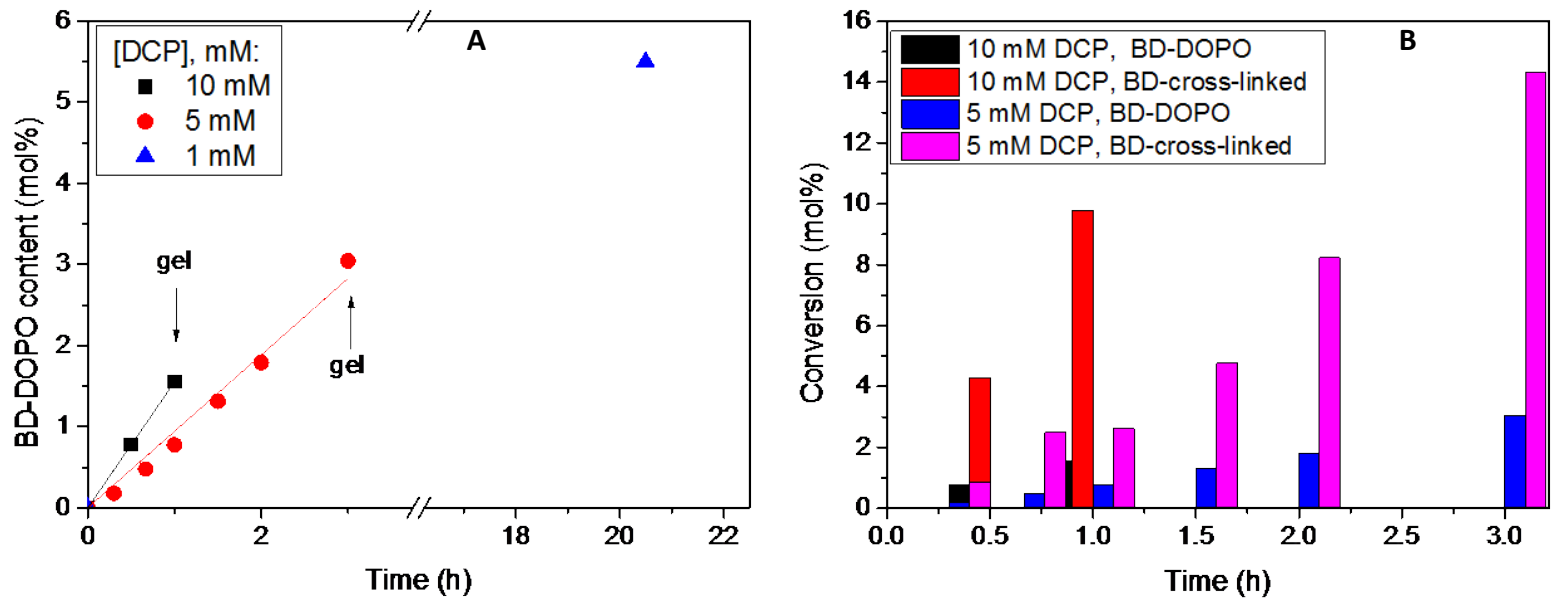

Figure 1. Free radical addition of DOPO to SBS. (A) Conversion of the butadiene units (BD) into the desired addition product (BD$\mathrm{DOPO}$ ) in time and (B) conversion of the BD into BD-DOPO as well as to cross-liked structures (BD-cross-liked)

In most cases, three times excess (1.2/0.4) of the modifier relative to olefinic units of SBS was used to ensure that the hydrogen abstraction from the modifier dominated over direct binding of the radicals from free radical initiator to the double bonds of SBS. From Table 1 it follows that lowering the ratio of modifier/double bonds to 1.5 (sample A10) leads to a decrease in the binding efficiency of DOPO to SBS at all otherwise equal conditions.

Stepwise addition of initiator was also attempted in order to overcome the gelation in the system at high concentration of free radical initiator. First, the free radical addition of DOPO was realized using $1 \mathrm{mM}$ of BPO initiator resulting in expectable low percentage of modification, i.e., 3.5 mol\% (Sample A11). After the completion of BPO decomposition (20 h), a fresh portion of initiator was added to the same reaction mixture so that its new concentration in the system was $10 \mathrm{mM}$ (sample A12). After $20 \mathrm{~h}$ the gelation of the polymer did not take place, because the concentration of double bonds prone to cross-linking had diminished after the first step of the free radical addition. At last, 
the procedure was repeated for the third time by modifying the remaining double bonds at $20 \mathrm{mM}$ of BPO (sample A13). That approach afforded the highest percent of the PBD block modification reported in the present work, that is, $21 \mathrm{~mol} \%$.

Table 1. Reaction conditions for modification of SBS with organophosphorus compounds. ${ }^{a}$

\begin{tabular}{|c|c|c|c|c|c|c|c|c|}
\hline No & $\begin{array}{l}\mathrm{P}-\mathrm{H} \\
\text { type }\end{array}$ & {$[\mathrm{P}-\mathrm{H}], \mathrm{M}$} & [In], mM & $\mathrm{T},{ }^{\circ} \mathrm{C}$ & $\mathrm{t}, \mathrm{h}$ & $\begin{array}{l}\text { Modification, } \\
\text { mol\% }\end{array}$ & $\begin{array}{l}\mathrm{Mn}, \\
\mathrm{kDa}\end{array}$ & PDI \\
\hline SBS & - & 0 & 0 & - & 0 & 0 & 258 & 1.2 \\
\hline A1 & DOPO & 1.2 & 10 (DCP) & 115 & 0.5 & 0.8 & 136 & 2.2 \\
\hline A2 & DOPO & 1.2 & 10 (DCP) & 115 & 1.0 & 1.8 & 134 & 3.1 \\
\hline A3 & DOPO & 1.2 & 5 (DCP) & 115 & 0.3 & 0.2 & 178 & 1.6 \\
\hline A4 & DOPO & 1.2 & 5 (DCP) & 115 & 0.7 & 0.5 & 190 & 1.8 \\
\hline A5 & DOPO & 1.2 & 5 (DCP) & 115 & 1.0 & 0.8 & 187 & 2.2 \\
\hline A6 & DOPO & 1.2 & 5 (DCP) & 115 & 1.5 & 1.3 & 150 & 2.7 \\
\hline A7 & DOPO & 1.2 & 5 (DCP) & 115 & 2.0 & 1.8 & 146 & 2.7 \\
\hline A8 & DOPO & 1.2 & 5 (DCP) & 115 & 3.0 & 3.0 & 108 & 2.3 \\
\hline A9 & DOPO & 1.2 & 1 (DCP) & 115 & 20 & 5.5 & 36 & 1.5 \\
\hline A10 & DOPO & 0.6 & 1 (DCP) & 115 & 20 & 3.6 & 78 & 2.6 \\
\hline${\mathrm{A} 11^{b}}^{b}$ & DOPO & 1.2 & 1 (BPO) & 70 & 20 & 3.5 & - & - \\
\hline $\mathrm{A} 12^{b}$ & DOPO & 1.2 & 10 (BPO) & 70 & 20 & 5.0 & - & - \\
\hline $\mathrm{A} 13^{b, c}$ & DOPO & 1.2 & 20 (BPO) & 70 & 20 & 21 & - & - \\
\hline B1 & DMPP & 1.2 & 1 (DCP) & 115 & 20 & 0.5 & - & - \\
\hline B2 & DMPP & 1.2 & 10 (DCP) & 115 & 20 & 0.6 & - & - \\
\hline C1 & DPP & 1.2 & 10 (DCP) & 115 & 16 & 0.6 & - & - \\
\hline C2 & DPP & 1.2 & 10 (LPO) & 80 & 16 & 0.6 & 55 & 2.4 \\
\hline C3 & DPP & 2.4 & 20 (LPO) & 80 & 16 & 1.0 & 56 & 2.8 \\
\hline C4 & DPP & 0.9 & 10 (AIBN) & 80 & 3 & 1.0 & 44 & 2.2 \\
\hline C5 & DPP & 0.9 & 30 (AIBN) & 80 & 3 & 1.1 & 36 & 1.9 \\
\hline
\end{tabular}

${ }^{a}$ Concentration of the olefinic fragments from SBS was fixed to $0.4 \mathrm{M}$ for all cases.

${ }^{b}$ Stepwise addition of BPO: first amount of BPO corresponding to its $1 \mathrm{mM}$ concentration was added, after $20 \mathrm{~h}$ at $70{ }^{\circ} \mathrm{C}$ another portion of BPO corresponding to its $10 \mathrm{mM}$ concentration was added and finally after additional $20 \mathrm{~h}$ at $70{ }^{\circ} \mathrm{C}$ the last portion of $\mathrm{BPO}$ was added yielding $20 \mathrm{mM}$ concentration of the peroxide in the reaction medium. ${ }^{c}$ The molecular weight could not be reliably determined due to sorption of the polymer on SEC column.

As for DMPP and DPP free radical addition to double bonds, the modification efficiency was found to be low for both reagents (0.5-1.1\%). The higher acidity of DMPP and hence its lower tendency for the homolytic P-H cleavage compared to DOPO ( $K_{\mathrm{a}}$ of DMPP and DOPO are ca. 20 and 21, respectively) ${ }^{17}$ may account for only $0.6 \%$ of the PBD modification with DMPP (Sample B2). On the contrary, the low polarity of P-H in the case of DPP favors the hydrogen abstraction by 
the free radical initiator, however, the resulting $\mathrm{P}$ centered radicals appear to be unreactive toward double bonds presumably due to the resonance stabilization by phenyl substituents of DPP. Also, attempts to vary the type and concentration of free radical initiator only led to $1.1 \mathrm{~mol} \%$ of modification.

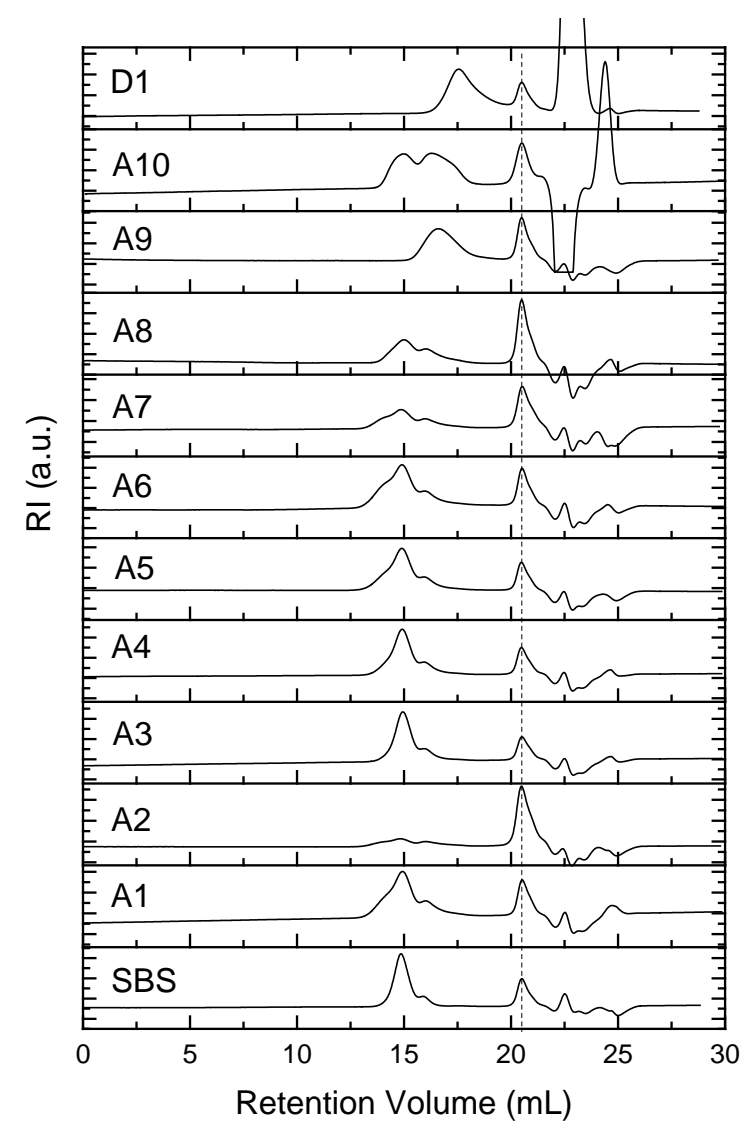

Figure 2. Representative GPC curves of the samples containing varied amount of organophosporus modifiers. The retention volume of the peak at $20.5 \mathrm{ml}$ corresponds to Irganox 1330 standard added during each GPC run.

Anionic addition of DPP-Li to halogenated SBS. SBS copolymer was subjected to a premodification step with $\mathrm{IBr}$ (Scheme 1, R2) in order to introduce good living groups $\left(\mathrm{I}^{-}\right.$and $\left.\mathrm{Br}^{-}\right)$ using the conditions described by Ceauşescu et al. ${ }^{14}$ The resulting halogenated product contained around $76 \%$ of $\mathrm{PBD}-\mathrm{IBr}$ and $24 \%$ of unreacted PBD double bonds as estimated by NMR (Supporting Information, SI2). The targeted degree of PBD modification was 90\%, so the efficiency of $\mathrm{IBr}$ reagent was estimated to be $85 \%$. The halogenated product was further subjected to nucleophilic substitution reaction with lithium diphenylphosphanide (DPP-Li) in the conditions 
specified in Table 2 (see also Scheme 1, R3). This procedure resulted in $6.8 \mathrm{~mol} \%$ of the DPP-Li addition to the PBD. Apart from addition of the DPP-Li, deleterious chain scission reaction took place as evidenced from the decrease in molecular weight of the modified SBS (Sample D1, Table 2).

Table 2. Ionic addition of the DPP-Li to halogenated SBS.

\begin{tabular}{lllllllll}
\hline No & P-H type & {$[\mathrm{P}-\mathrm{H}], \mathrm{M}$} & {$[\mathrm{In}], \mathrm{mM}$} & $\mathrm{T},{ }^{\circ} \mathrm{C}$ & $\mathrm{t}, \mathrm{h}$ & $\begin{array}{l}\text { Modification, } \\
\%\end{array}$ & $\begin{array}{l}\mathrm{Mn}, \\
\mathrm{kDa}\end{array}$ & PDI \\
\hline SBS & - & 0 & 0 & - & 0 & 0 & 258 & 1.2 \\
\hline D1 & DPP-Li & 0.9 & 0 & $0 \rightarrow 25$ & 16 & 6.8 & 15 & 1.4 \\
D2 & DPP-Li & 0.9 & 0 & $0 \rightarrow 50$ & 16 & 5.8 & - & - \\
\hline
\end{tabular}

Epoxidation of SBS followed by ring opening with P-containing reagents. Epoxidized SBS (SBS-epoxy) was used as a precursor for further immobilization of the P-containing reagents via ring opening addition to the epoxides (Scheme 1, R4). The epoxidation reaction itself was found primarily to affect 1,4 PBD chains due to 5 times lower activation energy for the epoxidation of 1,4cis double bonds of PBD compared to the epoxidation of 1,2-vinyl fragments of PBD. ${ }^{18}$ Thus, the epoxidized PBD block of SBS mainly contained 1,2-substituted epoxides (Supporting Information, SI3).

First, a direct reaction of SBS-epoxy with DOPO and DMPP was attempted in butanone at $90{ }^{\circ} \mathrm{C}$ (R5) in accordance with the procedure described by Liu et al. ${ }^{19}$ which resulted in less than $1 \%$ degree of modification due to the low acidity of the P-H bonds ( $\mathrm{p} K_{\mathrm{a}}$ of DOPO and DMPP are ca. 21 and 20 respectively). ${ }^{17}$ An even higher temperature was suggested in the literature $\left(160{ }^{\circ} \mathrm{C}\right)^{20}$ for analogous reaction between DOPO and monosubstituted epoxides in solvent free conditions, however, it was not tried in the present work due to the following reason: at elevated temperatures C-Si bond in the polymer backbone (originating from dichlorodimethylsilane linker used for SBS synthesis) may undergo homolytic cleavage thereby destroying the block copolymer structure itself. 
Using acids stronger than DOPO and DMPP, such as p-toluenesulfonic acid in chloroform ( $\mathrm{p} K_{\mathrm{a}}$ $=-2.8)$ and hydrochloric acid in THF $\left(\mathrm{p} K_{\mathrm{a}}=-7\right)$ resulted in quantitative conversion of the epoxides to the corresponding addition products in mild conditions $(\mathbf{R 6}) .{ }^{15}$ Hence, phosphoric acid $\left(\mathrm{p} K_{\mathrm{a} 1}=\right.$ 2.1) was deduced to be a suitable candidate for the role of phosphorus containing modifier (R7). Heating the THF solution of the SBS-epoxy (degree of epoxidation $=21$ mol\%) with equimolar relative to epoxy groups amount of $1 \mathrm{M} \mathrm{H}_{3} \mathrm{PO}_{4}$ to $50{ }^{\circ} \mathrm{C}$ did not significantly change the epoxy content in the polymer. However, an increase in the temperature $\left(80^{\circ} \mathrm{C}\right)$, reaction time $(16 \mathrm{~h})$ and concentration of $\mathrm{H}_{3} \mathrm{PO}_{4}(6 \mathrm{M})$ led to complete conversion of epoxides to the corresponding monoalkyl esters of phosphoric acid (Supporting Information, SI4). ${ }^{21}$ Even though the modified product could easily be dissolved in THF, analysis of the molecular weight by SEC was challenging due to irreversible adsorption of the hydrophilic-hydrophobic product onto the stationary phase [poly(styrene-divinylbenzene] of the chromatography column. The sample denoting SBS modified with $\mathrm{H}_{3} \mathrm{PO}_{4}$ is further abbreviated as E1.

The direct reaction of SBS-epoxy with 10-chloro-9-hydro-9-oxa-10-phosphaphenanthrene-10oxide (DOPO-Cl) obtained by oxidation of DOPO with trichloroisocyanuric acid was also performed (R8). ${ }^{22}$ The total percent of the PBD modification was $0.1 \%$. In spite of the fact that monosubstituted epoxides are known to react with chlorophosphates with ease, ${ }^{23}$ ring opening of 1,2-disubstituted epoxides was shown to be not feasible even when catalyzed by Lewis acids. $^{24}$ This fact in combination with preferred epoxidation of 1,4 over 1,2 chains ${ }^{18}$ of the PBD may account for the low degree of ring opening of the epoxy groups with DOPO-Cl reagent observed in the present studies.

The alternative route of incorporating DOPO into the polymer backbone encompassing intermediate ring opening of the epoxides with ethanolamine followed by reaction of the incorporated hydroxyl groups with DOPO-Cl with was also pursued (R9). As seen in the previous 
cases, the 1,2-substituted epoxides were not reactive toward ethanolamine mainly due to the bulky polymeric substituents which preclude $S_{N} 2$ type reaction. Even when SBS-epoxy was heated to 110 ${ }^{\circ} \mathrm{C}$ in the presence of large excess of ethanolamine in toluene the level of epoxides conversion was below 1\%. Stronger nucleophile such as deprotonated form of DOPO (DOPO-Li) was also unreactive toward 1,2-substituted epoxides (R10).

Hence, 2 out of 10 synthesis routes described above were selected as most viable approaches to covalently introduce the organophosporus substituents into the SBS structure. Namely, free radical addition of DOPO to SBS which afforded to vary the degree of PBD modification from 0.2 to 21 mol\% as well as the two step route encompassing (i) epoxidation followed by (ii) ring opening of the epoxides with phosphoric acid. The latter approach was utilized to incorporate only fixed amount of the monoalkyl ester of phosphoric into the PBD backbone predetermined by the epoxidation step, that is, $20 \mathrm{~mol} \%$.

TGA of the modified SBS copolymers. Thermal degradation behavior of unmodified SBS as well as DOPO and $\mathrm{H}_{3} \mathrm{PO}_{4}$ modified polymer was studied by TGA in air. The onset decomposition temperatures corresponding to the weight loss of $5 \%\left(T_{5 \%}\right)$ and $10 \%\left(T_{10 \%}\right)$ are summarized in Table 3. Also, from differential thermogravimetric curves (Supporting Information, SI5) the temperatures at which the decomposition rate acquires its local maximum $\left(T_{\max 1}, T_{\max 2}, T_{\max 3}\right)$ were determined (Table 3).

Unmodified SBS starts to degrade already at $350{ }^{\circ} \mathrm{C}$ as can be seen from the decomposition temperature corresponding to the $5 \%$ of the weight loss, $T_{5 \%}$. Thermal degradation rate reaches its first local maximum at $T_{\max 1}=365^{\circ} \mathrm{C}$ which signifies the degradation step of poly(styrene) blocks in SBS. ${ }^{25,26}$ Taking into account the ceiling temperature of styrene monomer $\left(395{ }^{\circ} \mathrm{C}\right){ }^{27}$, it is evident that both depolymerization and oxidative destruction of the poly(styrene) commences at this stage. Also, at $300-420^{\circ} \mathrm{C}$, i.e., when the slope of the TGA curve is steady, the weight loss is 30 
wt.\% which correlates well with the weight fraction of poly(styrene) blocks in SBS (32 wt.\%). The second degradation step at $T_{\max 2}=435{ }^{\circ} \mathrm{C}$ probably corresponds to the depolymerization/oxidative destruction of poly(butadiene) block as inferred from the ceiling temperature of 1,3 butadiene equal to $585{ }^{\circ} \mathrm{C} .{ }^{27}$ At last, thermal destruction of the harshly oxidized and cross-linked polymer residue takes place at $T_{\max 3}=476{ }^{\circ} \mathrm{C}$.
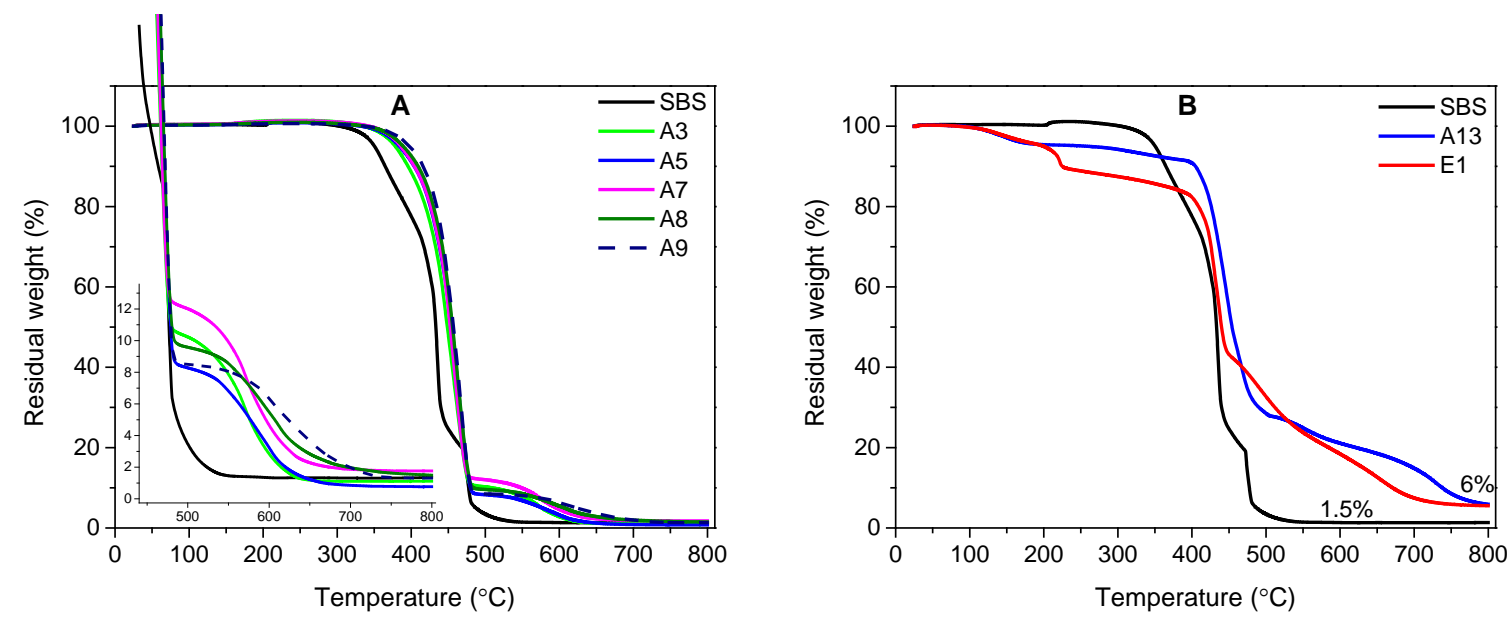

Figure 3. TGA of DOPO and $\mathrm{H}_{3} \mathrm{PO}_{4}$ modified SBS (A) at low (0.2-5.5\%) and (B) high (20-21\%) degree of modification of PBD block (in air, $10^{\circ} \mathrm{C} / \mathrm{min}$ ).

Thermal stability of DOPO modified SBS samples (A3, A5, A7, A8, A9) with low degree of PBD block modification (0.2, 0.8, 1.8, 3.0, 5.5 \% respectively) was found to be higher compared to that of unmodified SBS (Figure 2A). In particular, the decomposition temperatures corresponding to the weight loss of $5 \%\left(T_{5 \%}\right)$ and $10 \%\left(T_{10 \%}\right)$ are $50{ }^{\circ} \mathrm{C}$ higher for DOPO modified SBS (Table 3, sample A9) relative to its unmodified analog.

Such behavior is attributed to the effect of bulky DOPO substituents present in the main chain of modified SBS that hinder the relaxation processes and thereby increase the activation energy for the homolytic cleavage of the $\mathrm{C}-\mathrm{C}$ bonds in the polymer backbone. 
Table 3. TGA parameters for SBS modified with DOPO and $\mathrm{H}_{3} \mathrm{PO}_{4}$ residuals.

\begin{tabular}{|c|c|c|c|c|c|c|c|c|}
\hline Sample & $\begin{array}{l}\text { PBD } \\
\text { modification (\%) }\end{array}$ & $\begin{array}{l}T_{5 \%} \\
\left({ }^{\circ} \mathrm{C}\right)\end{array}$ & $\begin{array}{l}T_{10 \%} \\
\left({ }^{\circ} \mathrm{C}\right)\end{array}$ & $\begin{array}{l}T_{\max 1} \\
\left({ }^{\circ} \mathrm{C}\right)\end{array}$ & $\begin{array}{l}T_{\max 2} \\
\left({ }^{\circ} \mathrm{C}\right)\end{array}$ & $\begin{array}{l}T_{\max 3} \\
\left({ }^{\circ} \mathrm{C}\right)\end{array}$ & $\begin{array}{l}\text { Residue at } \\
550^{\circ} \mathrm{C} \text { (wt.\%) }\end{array}$ & $\begin{array}{l}\text { Residue at } \\
800^{\circ} \mathrm{C} \text { (wt.\%) }\end{array}$ \\
\hline SBS & 0 & 350 & 365 & 365 & 435 & 476 & 1.5 & 1.4 \\
\hline A9 & 5.5 & 398 & 416 & 466 & 602 & - & 8.0 & 1.3 \\
\hline $\mathrm{A} 13^{a}$ & 21 & 259 & 405 & 446 & 552 & 729 & 24.9 & 5.9 \\
\hline $\mathrm{E} 1^{b}$ & 20 & 200 & 225 & 434 & 492 & 655 & 23.8 & 5.5 \\
\hline
\end{tabular}

At high loadings of the fire retardant, 4 and 5 stage decomposition occurs for DOPO and $\mathrm{H}_{3} \mathrm{PO}_{4}$ modified SBS, respectively (samples A13 and E1). The decomposition of A13 the 100-400 ${ }^{\circ} \mathrm{C}$ temperature range results in $9 \%$ mass loss, whereas E1 loses $18 \%$ of its weight, probably due to occurrence of the cross-linking reactions between phosphate groups resulting in evolution of water. ${ }^{7}$ Also, evaporation of non-chemically bound water of hydration emanating from phosphate groups may lead to twice higher mass loss at $100-400{ }^{\circ} \mathrm{C}$ for sample E1. Similarly, polar phosphoryl groups $(\mathrm{P}=\mathrm{O})$ in the polymer sample $\mathrm{A} 13$ tend to be solvated by toluene and water and therefore retain these minor solvent components even after extensive vacuum drying at $50{ }^{\circ} \mathrm{C}$. After heating to $100{ }^{\circ} \mathrm{C}$ non-chemically bound impurities evaporate giving rise to the onset of weight loss at 100 ${ }^{\circ} \mathrm{C}$.

At higher temperatures, oxidative decomposition of poly(styrene) and poly(butadiene) blocks primarily accounts for further weight loss. In the case of unmodified SBS, the decomposition process is complete at $550{ }^{\circ} \mathrm{C}$ and only $1.5 \%$ of the initial weight remains. However, for phosphorus containing samples the decomposition process is competing with a so-called charring process which entails condensation reactions and formation of aromatic residue (char). The charring affords preservation of a significant fraction of material (25 and $24 \%$ for samples A13 and E1 respectively) at $550{ }^{\circ} \mathrm{C}$ that would otherwise be oxidized to volatile products. 
As shown in the literature, phosphorus containing substituents covalently incorporated into the polymer structure are capable to act as char promoting agents at elevated temperatures. ${ }^{28}$ Their mechanism of action implies the release of poly(phosphoric) acid which subsequently phosphorylates and dehydrates the organic material affording compact char. ${ }^{29-31}$ It is the barrier properties of the char that endow a material with higher thermal stability and resistivity to further combustion in the condensed state.

Cone calorimetry studies of the modified SBS. Unmodified SBS and $\mathrm{H}_{3} \mathrm{PO}_{4}$ modified SBS (sample E1) were tested under a heat flux from a cone heater providing a radiation exposure of 35 $\mathrm{kW} / \mathrm{m}^{2}$. The heat release rate (HRR) curve in Figure 4 shows that these specimens behave as thermally thick by having a secondary peak after the initial increase, and a plateau is reached before the backside of the samples are heated and starts to pyrolyse. ${ }^{32}$ The E1 decreased the peak heat release rate (PHRR) by as much as $60 \%$ and the initial growth by $28 \%$ with respect to unmodified SBS. The average heat release rate (AHRR) taken over the plateau from 60 to 120 seconds was 405 $\mathrm{kW} / \mathrm{m}^{2}$ for E1 whereas SBS released on average $565 \mathrm{~kW} / \mathrm{m}^{2}$ over the same period.

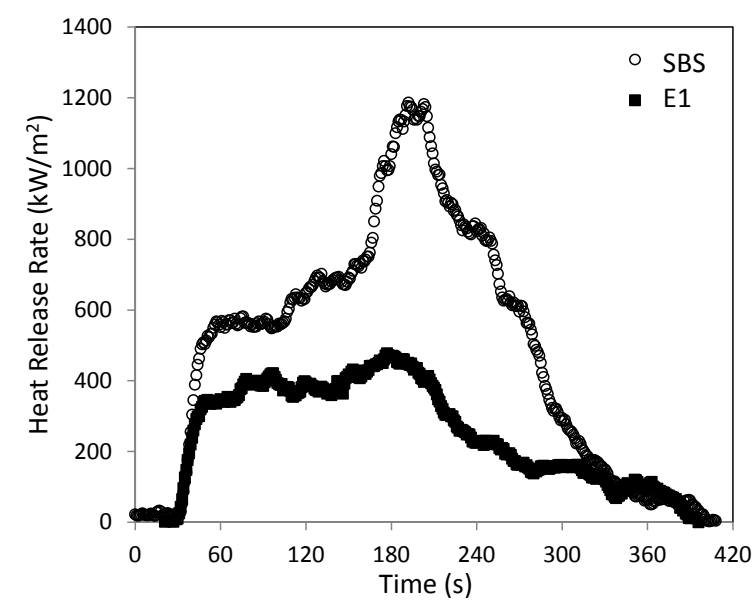

Figure 4. Heat release rate curves for unmodified and $\mathrm{H}_{3} \mathrm{PO}_{4}$ modified SBS exposed to $35 \mathrm{~kW} / \mathrm{m}^{2}$ 
A summary of the most important parameters characterizing the flammability of SBS and E1 are collected in Table 4.The flaming duration of the specimens were comparable, but the total energy released during this period was $196 \mathrm{MJ} / \mathrm{m}^{2}$ and $96 \mathrm{MJ} / \mathrm{m}^{2}$ for SBS and E1, respectively. The SBS specimen was completely consumed, whereas the E1 self-extinguished, leaving $20 \%$ of its initial mass in the sample holder (Figure 5). The initial mass loss rate for the first $120 \mathrm{~s}$ after ignition was $0.19 \mathrm{~g} / \mathrm{s}$ and $0.20 \mathrm{~g} / \mathrm{s}$ for SBS and E1, respectively, and thus almost identical. However, a large percentage of the mass of the samples was lost between $120 \mathrm{~s}$ and $180 \mathrm{~s}$ where there was a clear difference in the behaviour between the two samples. The SBS had an increasing mass loss rate, and it has lost a significant percentage of its mass in this period, whereas E1 had a decreasing mass loss rate in the same time period. From $180 \mathrm{~s}$ to burnout or self-extinguishing the mass loss rates were $0.133 \mathrm{~g} / \mathrm{s}$ and $0.064 \mathrm{~g} / \mathrm{s}$ for SBS and E1, respectively, which is more than a factor of 2 difference.

Table 4. Summary of important measured and calculated properties of SBS and E1 (5 x 100 x $100 \mathrm{~mm})$ as a result of an exposure to a heat flux of $35 \mathrm{~kW} / \mathrm{m}^{2}$

\begin{tabular}{lll}
\hline Parameter & SBS & E1 \\
\hline Time to ignition [s] & 41 & 47 \\
Time to peak heat release [s] & 192 & 177 \\
PHRR [kW/m2] & 1186 & 473 \\
AHRR from 60 to 120 s [kW/m²] & 565 & 405 \\
Mass Loss Rate (MLR) initial [g/s] & 0.19 & 0.202 \\
MLR final [g/s] & 0.133 & 0.064 \\
MLR initial [wt\%/s] & 0.0032 & 0.0035 \\
MLR final [wt\%/s] & 0.0023 & 0.0011 \\
Total Heat Release (THR) [MJ] & 196 & 96 \\
\hline
\end{tabular}

The visual difference between the two specimens after the exposure can be seen in the images shown in Figure 5, where it is evident that SBS has burned out and no residue was left whereas E1 created a char layer that prevented complete consumption of the sample. 

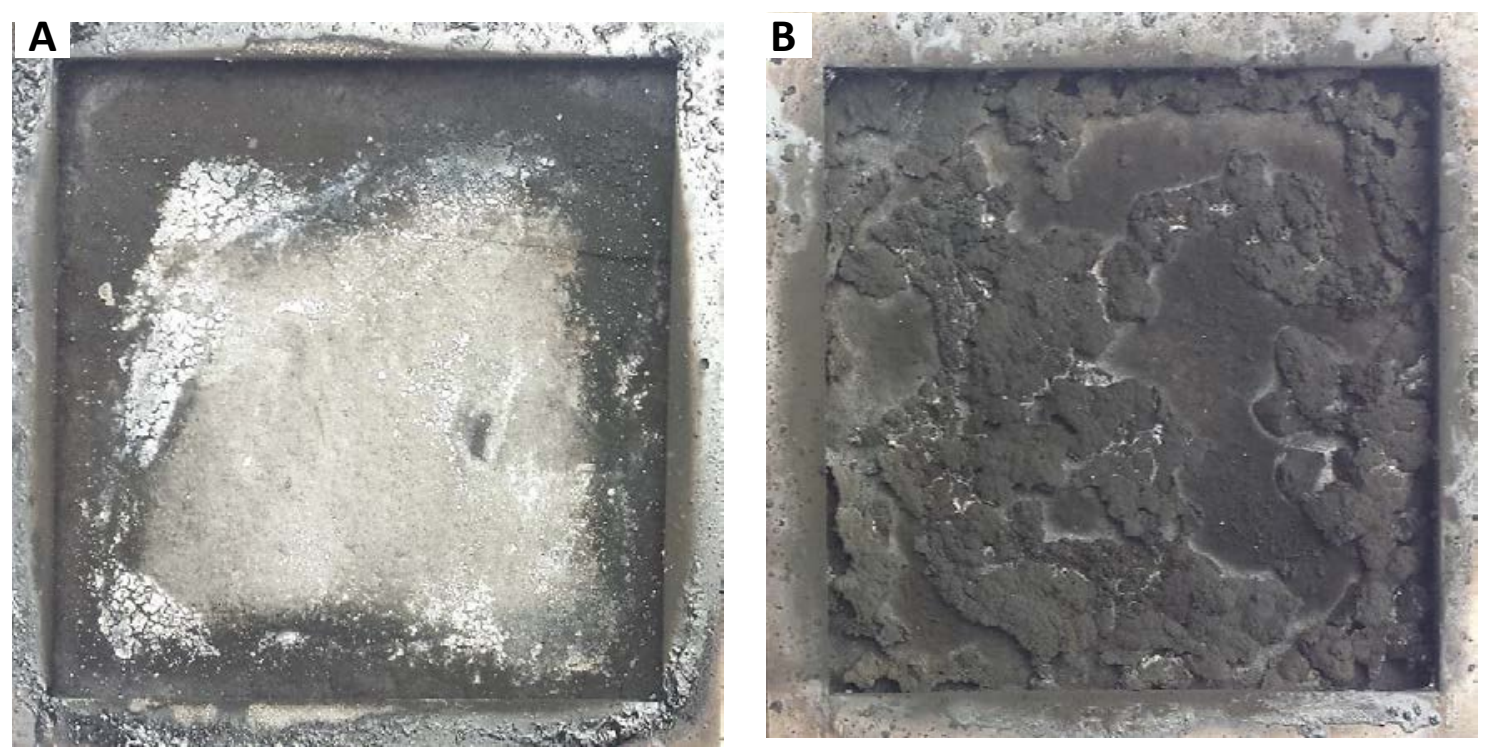

Figure 5. Optical images of the (A) unmodified and (B) $\mathrm{H}_{3} \mathrm{PO}_{4}$ modified SBS after cone calorimetry test.

Bitumen mixtures with modified SBS. The unmodified SBS constitutes the most widely used bitumen additive ${ }^{1}$ known to date, however, high flammability of SBS renders its chemical modification with a fire retardant species advantageous. Since $\mathrm{H}_{3} \mathrm{PO}_{4}$ modified SBS (E1) demonstrated a pronounced charring behavior during thermal degradation in air (see TGA and Cone calorimeter results), we anticipate that this property could be beneficial for further development of the fire retarded bitumen materials.

The data on flammability behavior of the pure bitumen and its mixture with modified SBS (E1) show similar average ignition time for both Mix1 and Mix2 while the average self-extinguishing time was reduced by $25 \%$ even at low loading of the fire retardant (Table 5). The amount of $\mathrm{H}_{3} \mathrm{PO}_{4}$ monoester which corresponds to the total 7 wt.\% of the modified SBS with the degree of modification equal to $22 \mathrm{wt}$ \% in the bitumen mixture is translated to $1.5 \mathrm{wt} . \%$ ( $7 \mathrm{x} 0.22)$ of $\mathrm{H}_{3} \mathrm{PO}_{4}$ monoester. Importantly, 1.5 wt.\% of $\mathrm{H}_{3} \mathrm{PO}_{4}$ monoester and 2 wt.\% of the melamine correspond to their 1:1 molar ratio. Equimolar amounts of the fire retardant species in Mix2 formulation afforded the formation of the polymeric fire retardant via deprotonation of the acidic phosphoric acid 
residues by the basic melamine species. The resulting melamine phosphate monoester therefore resembles a well-known and efficient fire retardant additive, namely melamine phosphate. ${ }^{33}$

Table 5. The composition of the bitumen mixtures and their flammability.

\begin{tabular}{llllllll}
\hline Sample & $\begin{array}{l}\text { Bitumen, } \\
\text { wt.\% }\end{array}$ & $\begin{array}{l}\text { Chalk, } \\
\text { wt.\% }\end{array}$ & $\begin{array}{l}\text { SBS, } \% \\
\text { wt. }\end{array}$ & $\begin{array}{l}\text { SBS- } \mathrm{H}_{3} \mathrm{PO}_{4}, \\
\text { wt.\% }\end{array}$ & $\begin{array}{l}\text { Melamine, } \\
\text { wt.\% }\end{array}$ & $\begin{array}{l}\text { Av. ignition } \\
\text { time, s }\end{array}$ & $\begin{array}{l}\text { Av. self- } \\
\text { extinguishing time, s }\end{array}$ \\
\hline Mix1 & 48 & 45 & 7 & 0 & 0 & 22.5 & 44 \\
Mix2 & 46 & 45 & 0 & 7 & 2 & 22.0 & 33 \\
\hline
\end{tabular}

The advantage in using melamine phosphate is exemplified by its dual mechanism of action. At elevated temperatures melamine sublimes and thus cools down the combustion zone while the released phosphoric acid results in phosphorylation and dehydration of the carbon rich material (bitumen) affording formation of carbonaceous char. As mentioned, the char layer opposes further propagation of fire due to its barrier properties. ${ }^{5,11,33,34}$

The amount of heat produced by the Epiradiator was not sufficient to ignite the samples, therefore the obtained results are semi-quantitative. However, from visual observation, the formation of bubbles (Figure 6) on a sample containing modified SBS indicated that the fire retardant, in addition to charring process, releases gases originating from melamine which dilute the combustion zone, - the phenomena also known as intumescence mechanism of action.

Furthermore, it is beyond the scope of the paper to elucidate whether $\mathrm{H}_{3} \mathrm{PO}_{4}$ modified SBS blended with bitumen and chalk alone, i.e., without melamine will impair the flammability of the resulting mixtures. Based on the pronounced fire retardant properties of $\mathrm{H}_{3} \mathrm{PO}_{4}$ modified SBS, as confirmed by cone calorimetry, we can only suppose that an improvement in flammability of the blend containing $\mathrm{H}_{3} \mathrm{PO}_{4}$ modified SBS, bitumen and chalk may be observed. 


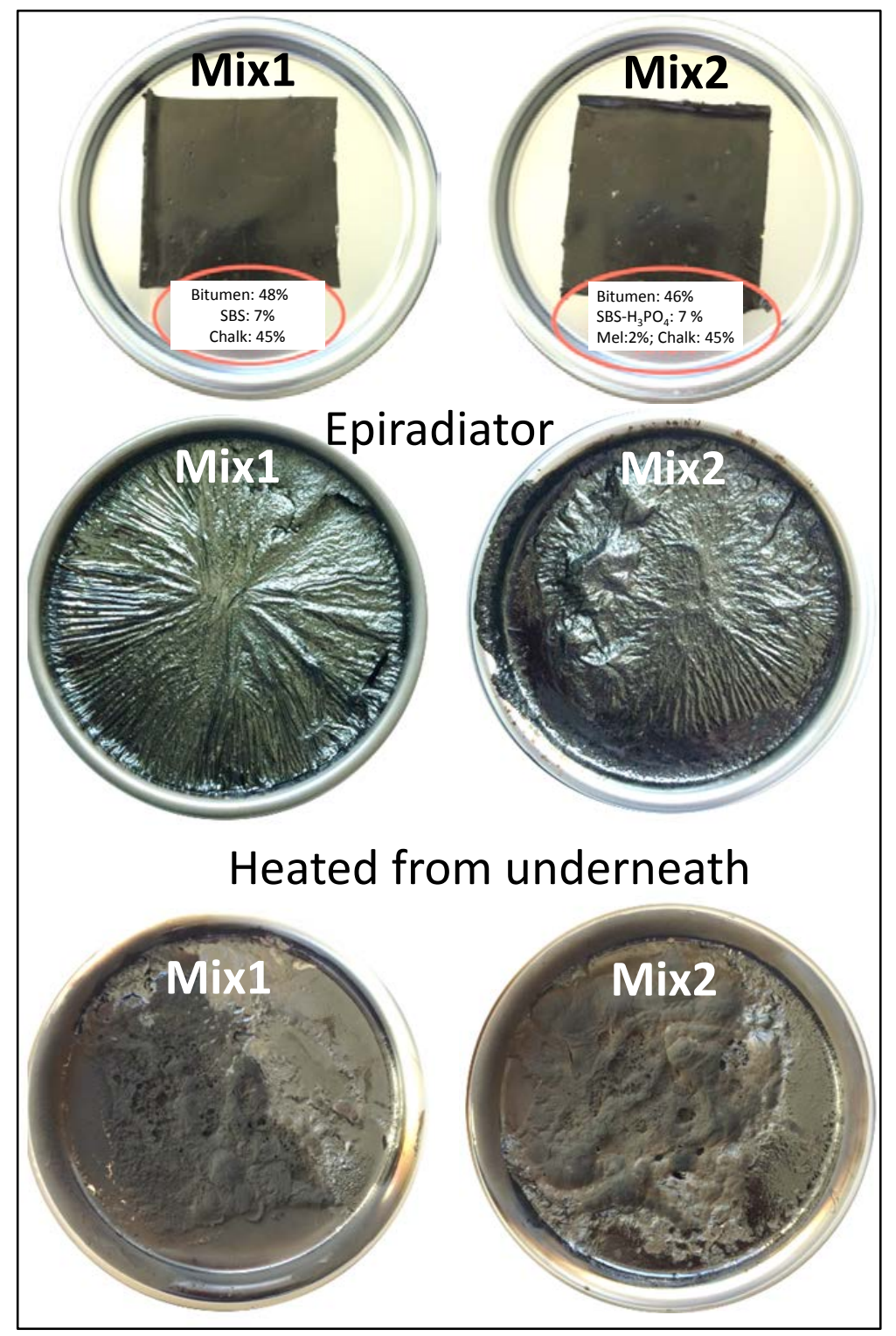

Figure 6. Bitumen mixtures before (two upper samples) and after (four lower samples) the flammability tests.

\section{Conclusions}

Free radical addition of P-H to poly(butadiene) block of SBS was optimized for DOPO modifier yielding $20 \mathrm{~mol} \%$ of the poly(butadiene) block modification on the condition that free radical initiator is added stepwise. Large excess of expensive DOPO modifier over the double bonds (3x) was needed to achieve high modification efficiency of poly(butadiene) block, which hindered 
further scale up of the procedure. On the contrary, relatively cheap and scalable process consisting of epoxidation of poly(butadiene) block followed by ring opening of the epoxides with phosphoric acid afforded preparation of a substantial quantity of $\mathrm{H}_{3} \mathrm{PO}_{4}$ modified SBS (200 g), with the degree of modification 21 mol\%. Compared to unmodified SBS, $\mathrm{H}_{3} \mathrm{PO}_{4}$ modified SBS increased the char yield in the $500-800{ }^{\circ} \mathrm{C}$ temperature range as well as decreased peak heat release rate by $60 \%$ and final mass loss rates by $52 \%$ evidencing that chemical alterations endowed SBS with enhanced fire resistance. Also, bitumen mixtures containing $\mathrm{H}_{3} \mathrm{PO}_{4}$ modified SBS and melamine selfextinguished 25\% faster even at low loadings of the polymeric retardant (3.5 wt.\%).

\section{Acknowledgements}

Authors are thankful to The Danish National Advanced Technology Foundation for the financial support of the Safe Flame Retardants (SRF) project.

\section{References}

(1) Airey, G. D. Rheological properties of styrene butadiene styrene polymer modified road bitumens. Fuel 2003, 82, 1709-1719.

(2) Schumacher, J. H.; Mills, D. L. Integral sole with footprint embossing. 1995, US5465507 A.

(3) Handlin, D. L.; Hansen, D. R.; Wright, K. J.; Trenor, S. R., Industrial Applications. In Controlled and Living Polymerizations, Wiley-VCH Verlag GmbH \& Co. KGaA: 2010; pp 555-603.

(4) Lao, S. C.; Wu, C.; Moon, T. J.; Koo, J. H.; Morgan, A.; Pilato, L.; Wissler, G. Flame-retardant Polyamide 11 and 12 Nanocomposites: Thermal and Flammability Properties. J. Compos. Mater. 2009, 43, 1803-1818.

(5) Bourbigot, S.; Duquesne, S. Fire retardant polymers: recent developments and opportunities. $J$. Mater. Chem. 2007, 17, 2283-2300.

(6) Weil, E. D.; Levchik, S. V. Flame retardants for polystyrenes in commercial use or development. $J$. Fire Sci. 2007, 25, 241-266.

(7) Banks, M.; Ebdon, J. R.; Johnson, M. Influence of covalently bound phosphorus-containing groups on the flammability of poly(vinyl alcohol), poly(ethylene-co-vinyl alcohol) and low-density polyethylene. Polymer 1993, 34, 4547-4556.

(8) Brosse, J. C.; Campistron, I.; Derouet, D.; El Hamdaoui, A.; Houdayer, S.; Reyx, D.; Ritoit-Gillier, S. Chemical modifications of polydiene elastomers: A survey and some recent results. J. Appl. Polym. Sci. 2000, 78, 1461-1477.

(9) Hoffmann, T.; Pospiech, D.; Häußler, L.; Komber, H.; Voigt, D.; Harnisch, C.; Kollann, C.; Ciesielski, M.; Döring, M.; Perez-Graterol, R.; Sandler, J.; Altstädt, V. Novel PhosphorousContaining Aromatic Polyethers - Synthesis and Characterization. Macromol. Chem. Phys. 2005, 206, 423-431. 
(10) Fu, B. X.; Lee, A.; Haddad, T. S. Styrene-Butadiene-Styrene Triblock Copolymers Modified with Polyhedral Oligomeric Silsesquioxanes. Macromolecules 2004, 37, 5211-5218.

(11) Lu, S.-Y.; Hamerton, I. Recent developments in the chemistry of halogen-free flame retardant polymers. Prog. Polym. Sci. 2002, 27, 1661-1712.

(12) Rohlík, Z.; Holzhauser, P.; Kotek, J.; Rudovský, J.; Němec, I.; Hermann, P.; Lukeš, I. Synthesis and coordination properties of palladium(II) and platinum(II) complexes with phosphonated triphenylphosphine derivatives. J. Organomet. Chem. 2006, 691, 2409-2423.

(13) Gulyás, H.; Benet-Buchholz, J.; Escudero-Adan, E. C.; Freixa, Z.; van Leeuwen, P. W. N. M. Ionic Interaction as a Powerful Driving Force for the Formation of Heterobidentate Assembly Ligands. Chem. Eur. J. 2007, 13, 3424-3430.

(14) Ceauşescu, E.; Bordeianu, R.; Buzdugan, E.; Cerchez, I.; Ghioca, P.; Stancu, R. Polybutadiene Modification: Reactions of Halogen-Containing Polybutadienes with Organolithium Compounds. $J$. Macromol. Sci.-Chem. 1985, 22, 803-818.

(15) Cameron, G. G.; Duncan, A. W. S. Chemical modification of polydienes, 1. Grafting of chlorohydrinated polybutadiene and nitrile rubbers with poly(tetrahydrofuran). Makromol. Chem. 1983, 184, 1153-1161.

(16) Pandit, R.; Michler, G. H.; Lach, R.; Grellmann, W.; Saiter, J. M.; Berkessel, A.; Adhikari, R. Epoxidation of Styrene/Butadiene Star Block Copolymer by Different Methods and Characterization of the Blends with Epoxy Resin. Macromol. Symp. 2014, 341, 67-74.

(17) Tsvetkov, E. N.; Terekhova, M. I.; Petrov, É. S.; Malevannaya, R. A.; Mesyats, S. P.; Shatenshtein, A. I.; Kabachnik, M. I. Equilibrium acidity of certain phosphoryl and thiophosphoryl PH-acids in dimethyl sulfoxide. B Acad Sci USSR CH+ 1978, 27, 1743-1746.

(18) Aguiar, M.; de Menezes, S. C.; Akcelrud, L. Configurational double bond selectivity in the epoxidation of hydroxy-terminated polybutadiene with m-chloroperbenzoic acid. Macromol. Chem. Phys. 1994, 195, 3937-3948.

(19) Liu, Y.-L.; Wu, C.-S.; Chiu, Y.-S.; Ho, W.-H. Preparation, thermal properties, and flame retardance of epoxy-silica hybrid resins. J. Polym. Sci., Part A: Polym. Chem. 2003, 41, 2354-2367.

(20) Wang, C. S.; Lin, C. H. Synthesis and properties of phosphorus-containing epoxy resins by novel method. J. Polym. Sci., Part A: Polym. Chem. 1999, 37, 3903-3909.

(21) Soutif, J.-C.; Brosse, J.-C. Modification au deuxième degré de polymères époxydés, 2. Addition de l'acide benzoïque sur polyènes époxydés. Makromol. Chem. 1984, 185, 839-846.

(22) Acharya, J.; Gupta, A. K.; Shakya, P. D.; Kaushik, M. P. Trichloroisocyanuric acid: an efficient reagent for the synthesis of dialkyl chlorophosphates from dialkyl phosphites. Tetrahedron Lett. 2005, 46, 5293-5295.

(23) Hadjichristidis, N.; Pispas, S.; Floudas, G., Synthesis of Block Copolymers by Chemical Modification. In Block Copolymers, John Wiley \& Sons, Inc.: 2003; pp 114-125.

(24) Ding, Y.; Hu, J. The synthesis of vicinal halohydrin phosphates via highly regioselective ring opening of epoxides with dialkyl halophosphate. J. Chem. Soc., Perkin Trans. 1 2000, 1651-1655.

(25) Price, D.; Pyrah, K.; Hull, T. R.; Milnes, G. J.; Ebdon, J. R.; Hunt, B. J.; Joseph, P. Flame retardance of poly(methyl methacrylate) modified with phosphorus-containing compounds. Polym. Degrad. Stab. 2002, 77, 227-233.

(26) Ebdon, J. R.; Hunt, B. J.; Joseph, P.; Konkel, C. S.; Price, D.; Pyrah, K.; Hull, T. R.; Milnes, G. J.; Hill, S. B.; Lindsay, C. I.; McCluskey, J.; Robinson, I. Thermal degradation and flame retardance in copolymers of methyl methacrylate with diethyl(methacryloyloxymethyl)phosphonate. Polym. Degrad. Stab. 2000, 70, 425-436.

(27) Matyjaszewski, K.; Franz, U.; Montague, R. A.; White, M. L. Synthesis of polyphosphazenes from phosphoranimines and phosphine azides. Polymer 1994, 35, 5005-5011.

(28) Schartel, B. Phosphorus-based Flame Retardancy Mechanisms-Old Hat or a Starting Point for Future Development? Materials 2010, 3, 4710-4745.

(29) Ma, H.; Tong, L.; Xu, Z.; Fang, Z.; Jin, Y.; Lu, F. A novel intumescent flame retardant: Synthesis and application in ABS copolymer. Polym. Degrad. Stab. 2007, 92, 720-726.

(30) Mikhailine, A. A.; Maishan, M. I.; Lough, A. J.; Morris, R. H. The Mechanism of Efficient Asymmetric Transfer Hydrogenation of Acetophenone Using an Iron(II) Complex Containing an 
$(\mathrm{S}, \mathrm{S})-\mathrm{Ph} 2 \mathrm{PCH} 2 \mathrm{CH}=\mathrm{NCHPhCHPhN}=\mathrm{CHCH} 2 \mathrm{PPh} 2$ Ligand: Partial Ligand Reduction Is the Key. $J$. Am. Chem. Soc. 2012, 134, 12266-12280.

(31) Chernyy, S.; Ulah, S.; Sørensen, G.; Tordrup, S. W.; Pedersen, P. B.; Almdal, K. DOPO-VTS-based coatings in the realm of fire retardants for cotton textile. J. Appl. Polym. Sci. 2015, 132, 41955.

(32) Bernhard, S., Uses of Fire Tests in Materials Flammability Development. In Fire Retardancy of Polymeric Materials, Second Edition, CRC Press: 2009; pp 387-420.

(33) Camino, G.; Costa, L.; Martinasso, G. Intumescent fire-retardant systems. Polym. Degrad. Stab. 1989, 23, 359-376.

(34) Laoutid, F.; Bonnaud, L.; Alexandre, M.; Lopez-Cuesta, J. M.; Dubois, P. New prospects in flame retardant polymer materials: From fundamentals to nanocomposites. Mater. Sci. Eng. R-Rep. 2009, 63, 100-125. 